\title{
FALLS AND ITS ASSOCIATED FACTOR AMONG THE ELDERLY: RESULTS FROM AN ELDERLY SCREENING PROGRAMME IN KELANTAN
}

\author{
Wafaak $\mathrm{E}^{1,2}$, Noran $\mathrm{H}^{3}$ and Hamid NA ${ }^{1}$ \\ ${ }^{1}$ Department of Community Medicine, School of Medical Sciences, Science University of Malaysia, ${ }^{2}$ Ministry \\ of Health Malaysia, ${ }^{3}$ Kelantan Health Department
}

Corresponding author: Noor Aman A.Hamid

Email: na.hamid@usm.my

\begin{abstract}
Falls in the elderly is one of the health issues. The aims of this study were to determine the prevalence of fall among the elderly and its associated factor. This was cross-sectional retrospective record review study. Data from the elderly health screening programme of government health clinics in Kota Bharu, Kelantan were obtained. All elderly who participated in the programme for year 2014 was eligible. Multiple logistic regression was used to assess for associated factors of falls with self-reported fall events. Data for $n=434$ participants were retrieved. The prevalence of falls among elderly who participated in the health screening programme was $23.3 \%$ (95\% Cl: 0.19, 0.27). This study demonstrated that falls was associated with age more than 80 years old (OR adj 32.20, 95\% Cl: 8.54, 121.39; $p<0.001$ ), being female (OR adj 0.46, 95\% Cl: 0.24, 0.87; $p=0.017$ ), being employed (OR adj 0.04, 95\% Cl: 0.01, 0.26; $p=0.001$ ), obesity (OR adj 2.65, 95\% Cl: 1.20, 5.86; $p=0.016$ ), symptoms of dizziness (OR adj 6.77, 95\% Cl: 1.39, 32.98; $p=0.018$ ), imbalance and instability (OR adj 9.92, 95\% Cl: 1.39, 32.98; $p<0.001)$, polypharmacy (OR adj 4.72, 95\% Cl: 1.20, 5.86; $p=0.001$ ) and increased waist circumference (OR adj $2.54,95 \% \mathrm{Cl}: 1.29,5.01 ; p=0.007$ ). This study demonstrated that the prevalence of falls among elderly is still an issue and its associated factors should be intervened.
\end{abstract}

Keywords: Associated factor, Elderly, Fall, Health screening,

\section{INTRODUCTION}

Malaysia is undergoing an epidemiological transition which has resulted in an increase in the elderly population and consequently, burden of chronic diseases. Now, Malaysian population who aged 65 years and over reach $7.0 \%$ of the population and expected to reach $14.5 \%$ by the year $2040^{1,2}$.

Falls in the elderly is one of the health issues. Prevalence of falls among the elderly in Malaysia varies from $18.8 \%$ to $27.3 \%^{3,4}$. Falls may lead to catastrophic events such as hip fracture, thus contributing to chronic conditions of the elderly. This eventually will limit the quality of life and physical health of the elderly.

Falls is a preventable condition and often multifactorial. Studies in Malaysia showed that an age, gender, medical illness and medications were associated with fall among the elderly ${ }^{3,5}$. Obesity is one of the factors for fall among the elderly ${ }^{6}$. However, several studies looking into the association between obesity and falls among the elderly have produced mixed findings ${ }^{6-8}$. As prevalence of obesity among the Malaysian elderly was $30.2 \%$, thus there is a need to embark on a study to ascertain the factors which may influence falls including weight issues. Thus, it allow screening, early detection and interventions to be put in place in the prevention of falls. The objectives of this study were to determine the prevalence of falls among the elderly in a community and its associated factor.

\section{METHODS}

A cross-sectional retrospective record review study was conducted in all government health clinics in Kota Bharu district, Kelantan. The state of Kelantan, located at north-east region of Peninsular Malaysia, has 10 districts including Kota Bharu, the state capital. The total population in Kota Bharu was approximately 491,237 people, or $32 \%$ of the Kelantan population. In Kelantan, $8.8 \%$ of population was made up of elderly in 2010 with $30 \%$ of the elderly living in the Kota Bharu area?.

All elderly aged 60 years and above who participated in the health screening programme in health clinics in Kota Bharu district between $1^{\text {st }}$ January 2014 and 31 $31^{\text {st }}$ December 2014 were included in the study except for those who were bedridden, immobile or living in institutions. This study used data from a health screening programme for the elderly which was conducted by trained health personnel in each health clinics ${ }^{10}$. Entry points for this screening programme were walk-in patients and from the out-patient clinic. The screening forms were reviewed and the information for history of fall, sociodemography, clinical characteristics, Get Up and Go Test, anthropometric measurement and lifestyle were extracted. 
Falls among the elderly was based on self reported 'ever fall' as stated in the screening form. Age was categorized into young-elderly (60-74 years old) and old-elderly ( $\geq 75$ years old $)^{11}$. Employment status was categorized into employed and nonemployed at the time of screening. Housewife and retired elderly were categorized into the same group with non-employed. Physically active was self-reported and defined as performing exercise such as cycling, jogging, and swimming or any physical activity such as gardening, or walking at least for 30 minutes for 3 days or more per week.

Smoking or alcohol consumption was based on self-reporting by the participants. Presences of diseases such as diabetes mellitus, hypertension, coronary heart disease or chronic lung diseases were based on self-reporting by the elderly. Usually this would entail the diseases been diagnosed clinically and informed by a clinician. Clinical symptoms such as cognitive problem, weakness and dizziness were based on selfreporting. Polypharmacy was defined as 'use of four or more types of medications',3,4. Medication such anti-diabetes, anti-hypertension, cardiogenic or anti-depression medications were also recorded.

The Body Mass Index (BMI) was categorized into underweight $\left(\mathrm{BMl}<18.50 \mathrm{~kg} / \mathrm{m}^{2}\right)$, normal weight (BMI $\left.\geq 18.50-22.99 \mathrm{~kg} / \mathrm{m}^{2}\right)$, overweight $(B M I \geq$ $\left.23.00-27.49 \mathrm{~kg} / \mathrm{m}^{2}\right)$ and obese (BMI $\geq 27.50$ $\left.\mathrm{kg} / \mathrm{m}^{2}\right)^{12}$. The Body Mass Index is a simple index of weight-for-height that is commonly used to classify overweight and obesity. It is still wellaccepted and used to measure obesity in elderly ${ }^{13}$. Waist circumference is high if $\geq 80 \mathrm{~cm}$ for women and $\geq 90 \mathrm{~cm}$ for men ${ }^{12}$. Systolic blood pressure were categorized as optimal if SBP $<120$ $\mathrm{mmHg}$ and not optimal if SBP $\geq 120 \mathrm{mmHg}^{14}$. Diastolic blood pressure were categorized as optimal if DBP $<80 \mathrm{mmHg}$ and not optimal if DBP $\geq 80 \mathrm{mmHg}^{14}$. Elderly with any difficulty or problem during Get up and go test was categorised into normal and imbalance ${ }^{15}$.

The data analysis was done using IBM- SPSS statistics. Data on sociodemography, clinical characteristics and lifestyle variables were categorized and summarized in frequency $(n)$ and percentage (\%). Outcome of interest for this study was self-declared fall episodes versus no falls ${ }^{1}$.

Multiple logistic regression was applied to answer the objectives of the study. Variables with a pvalue $<0.25$ from univariable analysis or of biological importance were selected for multiple logistic regressions. Strategy for building the models was based on Himes and Reynolds (2012) which effects sequential logistic regression model was used'. This was based on the 'enter' method with model one (sociodemographic factors), model 2 (sociodemographic and BMI), model 3 (sociodemographic, BMI and medical conditions) and model 4 (sociodemographic, BMI, medical conditions and other medical conditions).

Ethical approval for this study was obtained from the Human Ethics Committee, Universiti Sains Malaysia (USM/JEPeM/14120518) and the Medical Research and Ethics Committee, Ministry of Health, Malaysia (NMRR-14-1617-23636).

\section{RESULTS}

The study population consisted of $n=434$ subjects from 12 health clinics in Kota Bharu, Kelantan. Sociodemographic, clinical and lifestyle characteristics of the elderly who participated in health screening programme were shown in Tables 1 and 2. Majority of them were female, Malays and between the 60-75 years age group. Most of them were unemployed, retired or housewife. Nearly half of the elderly (46\%) were diagnosed or reported to have hypertension and $30 \%$ were diagnosed or reported to have diabetes mellitus. About $13 \%$ of the elderly were polypharmacy. A quarter of the elderly were on diabetes medications and half were on antihypertensive. Majority of the elderly $(69 \%)$ had $\mathrm{BMI}$ above the normal level. Most of the elderly had non-optimal blood pressure. About $60.5 \%$ of the elderly had recommended waist circumference.

The prevalence of self-reported falls among the elderly who were involved in the health screening programme in health clinic in Kota Bharu between January and December 2014 was 23.3\% (95\% Cl $0.19,0.27)$. Of those who fall, majority of them (78\%) had BMI above the normal value. The highest prevalence of fall was among the obese group $(46.7 \%)$ compared to overweight $(15 \%)$, normal (17.9\%) and underweight (10.7\%).

In the simple logistic regression, the significant associated factors of falls were age, employment status, diabetes mellitus, dizziness, polypharmacy, taking diabetes drugs, obesity, increased waist circumference and, imbalance and instability. In the multiple logistic regression models (Table 3), Model 1 showed that age and working status were associated with falls. The older age group (75 years old and above) had higher risk of falls compared to the younger age group (OR adj 4.11, 95\% Cl: 2.38, 7.09; $p<0.001$ ). Elderly who were still employed had lower odds of falls as compared to elderly who were unemployed/pension/housewives (OR adj 0.22, 95\% Cl: 0.07, 0.76; $p=0.017$ ).

In Model 2, obesity was still associated with a higher risk of falls (OR adj $4.20,95 \% \mathrm{Cl}: 2.15$, $8.20 ; p<0.001)$ after adjusting for sociodemograpic factors such as age, sex and employment status. Being underweight and overweight was not associated with a higher risk of falls. 
After adjusting for sociodemographic factors and health problems such as dizziness and imbalance during performing 'get up and go test' (Model 3), obesity remained a risk for falls (OR adj 3.30, 95\% $\mathrm{Cl}: 1.66,6.59 ; p=0.001)$. Both health problems; dizziness, imbalance in 'Get up and go test' also increased the odds of falls.

In the final model (Model 4), the odds of falls in the obese group had decreased but remained significant (OR adj 2.30, 95\% Cl: 1.06, 4.98; $p=$ $0.035)$. Being female (OR adj $0.48,95 \% \mathrm{Cl}: 0.25$, $0.91 ; p=0.024$ ) and employed (OR adj $0.062,95 \%$
$\mathrm{Cl}: 0.01,0.41 ; p=0.004)$ were associated with lower risk of falls. Other factors associated with falls were the old-elderly (OR adj $5.63,95 \% \mathrm{Cl}$ : $2.90,10.90 ; p<0.001)$ and symptoms of dizziness (OR adj 11.35, 95\% Cl: 2.19, 58.70; $p=0.004$ ). Having an abnormal waist circumference (OR adj 2.70, $95 \% \mathrm{Cl}: 1.38, \quad 5.28 ; \quad p=0.004)$ and polypharmacy (OR adj $3.56,95 \% \mathrm{Cl}: 1.26,10.09$ oy; $p=0.017$ ) also increased the risk of falls. Elderly with poor balance during the 'get up and go test' also had higher risk of falls (OR adj $8.75,95 \% \mathrm{Cl}$ : 2.71, 28.21; $p<0.001$ ).

Table 1 : Sociodemographic and lifestyle characteristics of the elderly according to experience of falls in Kota Bharu, Kelantan

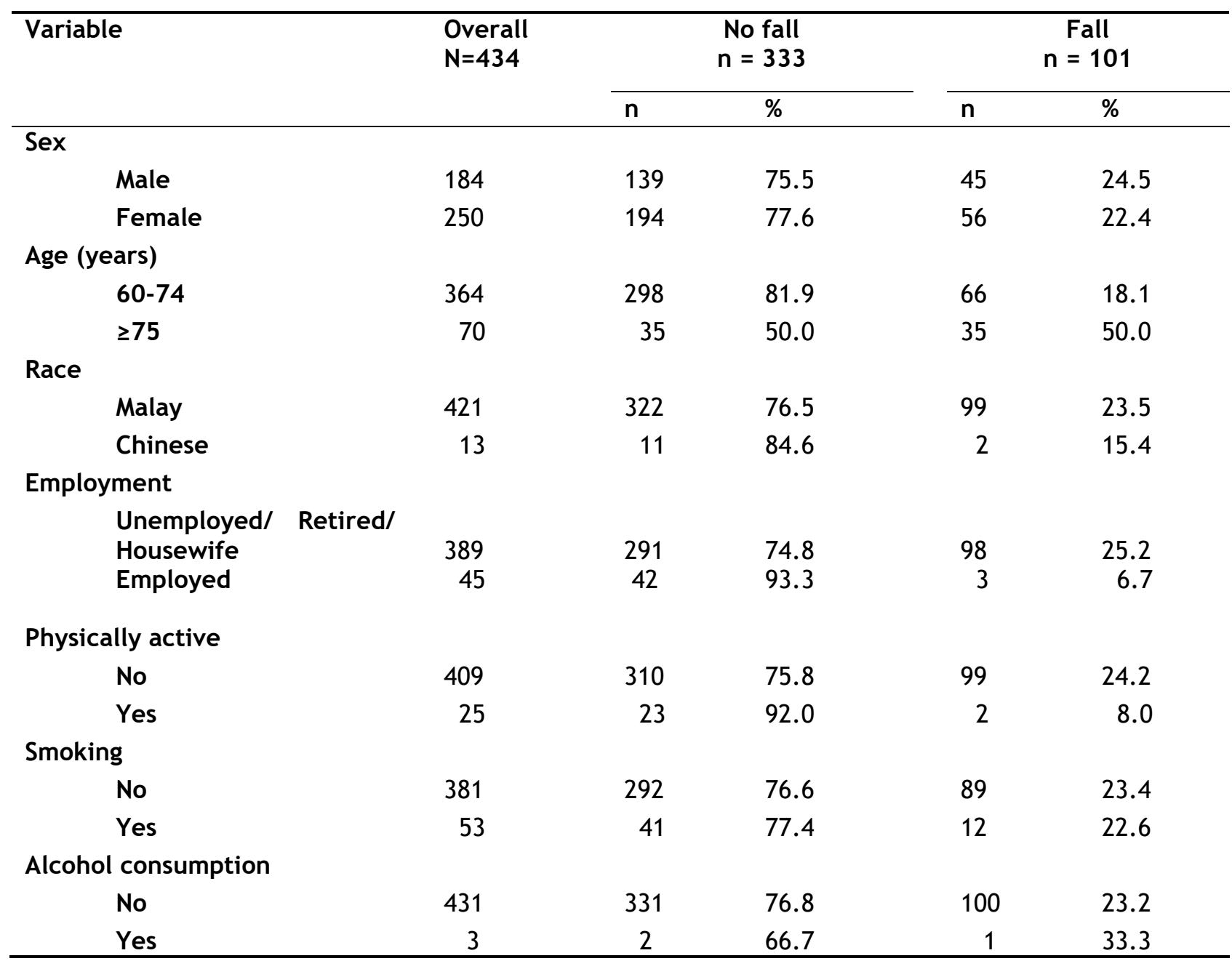

\section{DISCUSSION}

The prevalence of self-reported falls among elderly screened in health clinics in Kota Bharu was comparable to other local community-based study ${ }^{4}$. When compared to studies in other Asian countries, prevalence of falls in this study was very close to study in Taiwan ( $23.3 \%$ vs $22.7 \%$ ) which was conducted among elderly who received annual health examination ${ }^{16}$.
This study showed that obese elderly were more likely to falls than other body mass index (BMI) group, even after adjusting for chronic conditions and health problems. Previous research has also consistently demonstrated similar association ${ }^{6-8}$. This study compared risk of fall between all four BMI groups which were underweight, normal, overweight and obesity based on an Asian population which most recommended and established used in Malaysia according to risk of comorbidities ${ }^{17,18}$. 
Table 2a: Clinical characteristics of the elderly according to experience of falls in Kota Bharu, Kelantan

\begin{tabular}{|c|c|c|c|c|c|}
\hline \multirow[t]{2}{*}{ Variable } & \multirow[t]{2}{*}{$\begin{array}{l}\text { Overall } \\
\mathrm{N}=434\end{array}$} & \multicolumn{2}{|c|}{$\begin{array}{l}\text { No fall } \\
n=333\end{array}$} & \multicolumn{2}{|c|}{$\begin{array}{c}\text { Falls } \\
\mathrm{n}=101\end{array}$} \\
\hline & & $\mathrm{n}$ & $\%$ & $\mathrm{n}$ & $\%$ \\
\hline \multicolumn{6}{|l|}{ Diabetes Mellitus } \\
\hline No & 306 & 249 & 81.4 & 57 & 18.6 \\
\hline Yes & 128 & 84 & 65.6 & 44 & 34.4 \\
\hline \multicolumn{6}{|l|}{ Hypertension } \\
\hline No & 236 & 189 & 80.1 & 47 & 19.9 \\
\hline Yes & 198 & 144 & 72.2 & 54 & 27.3 \\
\hline \multicolumn{6}{|c|}{ Coronary heart disease } \\
\hline No & 424 & 325 & 76.7 & 99 & 23.3 \\
\hline Yes & 10 & 8 & 80.0 & 2 & 20.0 \\
\hline \multicolumn{6}{|c|}{ Chronic lung disease } \\
\hline No & 414 & 318 & 76.8 & 96 & 23.2 \\
\hline Yes & 20 & 15 & 75.0 & 5 & 25.0 \\
\hline \multicolumn{6}{|l|}{ Depression } \\
\hline No & 430 & 329 & 76.5 & 101 & 23.5 \\
\hline Yes & 4 & 4 & 100 & 0 & 0.0 \\
\hline \multicolumn{6}{|l|}{ Memory problem } \\
\hline No & 419 & 323 & 77.1 & 96 & 22.9 \\
\hline Yes & 15 & 10 & 66.7 & 5 & 33.3 \\
\hline \multicolumn{6}{|l|}{ Body weakness } \\
\hline No & 423 & 325 & 76.8 & 98 & 23.2 \\
\hline Yes & 11 & 8 & 72.7 & 3 & 27.3 \\
\hline \multicolumn{6}{|l|}{ Dizziness } \\
\hline No & 420 & 329 & 78.3 & 91 & 21.7 \\
\hline Yes & 14 & 4 & 28.6 & 10 & 71.4 \\
\hline \multicolumn{6}{|l|}{ Polypharmacy } \\
\hline$<4$ medications & 379 & 307 & 81.0 & 72 & 19.0 \\
\hline$\geq 4$ medications & 55 & 26 & 47.3 & 29 & 52.7 \\
\hline \multicolumn{6}{|c|}{ Diabetic medication } \\
\hline No & 323 & 265 & 82.0 & 58 & 18.0 \\
\hline Yes & 111 & 68 & 61.3 & 43 & 38.7 \\
\hline \multicolumn{6}{|c|}{ Anti-hypertensive medication } \\
\hline No & 224 & 179 & 79.9 & 45 & 20.1 \\
\hline Yes & 210 & 154 & 73.3 & 56 & 26.7 \\
\hline \multicolumn{6}{|c|}{ Cardiogenic medication } \\
\hline No & 425 & 326 & 76.7 & 99 & 23.3 \\
\hline Yes & 9 & 7 & 77.8 & 2 & 22.2 \\
\hline \multicolumn{6}{|c|}{ Anti-depression medication } \\
\hline No & 430 & 329 & 76.5 & 101 & 23.5 \\
\hline Yes & 4 & 4 & 100 & 0 & 0.0 \\
\hline \multicolumn{6}{|l|}{ Body Mass Index } \\
\hline Underweight & 28 & 25 & 89.3 & 3 & 10.7 \\
\hline Normal & 106 & 87 & 82.1 & 19 & 17.9 \\
\hline Overweight & 193 & 164 & 85.0 & 29 & 15.0 \\
\hline Obese & 107 & 57 & 53.3 & 50 & 46.7 \\
\hline
\end{tabular}


Malaysian Journal of Public Health Medicine 2021, Vol. 21 (2): 141-148

Table 2b: Clinical characteristics of the elderly according to experience of falls in Kota Bharu, Kelantan

\begin{tabular}{|c|c|c|c|c|c|}
\hline \multirow[t]{2}{*}{ Variable } & \multirow[t]{2}{*}{$\begin{array}{l}\text { Overall } \\
\mathrm{N}=434\end{array}$} & \multicolumn{2}{|c|}{$\begin{array}{c}\text { No fall } \\
n=333\end{array}$} & \multicolumn{2}{|c|}{$\begin{array}{l}\text { Falls } \\
n=101\end{array}$} \\
\hline & & $\mathrm{n}$ & $\%$ & $\mathrm{n}$ & $\%$ \\
\hline \multicolumn{6}{|l|}{ Waist circumference } \\
\hline Recommended & 263 & 222 & 84.4 & 41 & 15.6 \\
\hline High & 171 & 111 & 64.9 & 60 & 35.1 \\
\hline \multicolumn{6}{|l|}{ Systolic blood pressure } \\
\hline$<120 \mathrm{mmHg}$ & 44 & 34 & 77.3 & 10 & 22.7 \\
\hline$\geq 120 \mathrm{mmHg}$ & 390 & 299 & 76.7 & 91 & 23.3 \\
\hline \multicolumn{6}{|l|}{ Diastolic blood pressure } \\
\hline$<80 \mathrm{mmHg}$ & 224 & 176 & 78.6 & 48 & 21.4 \\
\hline$\geq 80 \mathrm{mmHg}$ & 210 & 157 & 74.8 & 53 & 25.2 \\
\hline \multicolumn{6}{|l|}{ Get up and go test } \\
\hline $\begin{array}{l}\text { Normal } \\
\text { Imbalance }\end{array}$ & $\begin{array}{r}405 \\
28\end{array}$ & $\begin{array}{r}322 \\
11\end{array}$ & $\begin{array}{l}79.5 \\
39.3\end{array}$ & $\begin{array}{l}83 \\
17\end{array}$ & $\begin{array}{l}20.5 \\
60.7\end{array}$ \\
\hline
\end{tabular}

Body weight is a strong predictor of postural stability. Obese elderly had higher prevalence of ambulatory stumbling as compared to non-obese groups which suggested that they may have inadequate postural stability ${ }^{7}$. They also have abnormal body fat-muscle composition and distribution with decrease in muscle mass and, increase in fat mass in muscles and visceral abdominal fat ${ }^{13,17}$. Besides instability, those with increased body mass index were also more likely to have exhaustion, weakness, reduced walking velocity and decreased activity level ${ }^{19}$. Comorbidity such as heart disease, diabetes, arthritis, depression and anxiety has being identified as a mediator for the relationship ${ }^{8}$. Thus they tend to have a lower quality of life and frail ${ }^{7}$. This study has shown, even after adjusting for these conditions, obesity itself is a risk for falls.

This study also found that waist circumference was associated with falls among the elderly. The elderly who had increased waist circumference which related to abdominal obesity have higher risk of falls ${ }^{16}$. High waist circumference may also indicate the lack of physical activity and frailty ${ }^{20}$, whether direct or indirectly. Those with high waist circumferences were frailer which then increase the chances of falls. Although other studies use different cut of points based on the standard recommendation of the respective country, high waist circumference was consistently associated with risk of falls among the elderly.

For sociodemographic factor, this study found age as a predictor of falls, however being female and employed was a protective factor. The older elderly ( $\geq 75$ years old) were found to be at the highest risk of falls. Older aged elderly were more likely to fall due to risk of instability and frailty compared to younger aged group ${ }^{6,11}$. Females commonly report fear of falling and avoid engaging in outdoor activities or stayed immobile, especially in rural areas which protect them from other environmental risk $^{21}$. There were limited studies looking at employment status as the risk factor of falls among the elderly. Most of the employed elderly in this study are still working as farmers, doing odd works and running own businesses. Employment status among the elderly may indicate the elderly mobility and physical activity status, suggesting indirectly that they may be more active and associated with low body fat and improved cardiovascular fitness which decreased the risk of falls ${ }^{22}$.

For physical health, those who has dizziness and unable to perform the "get up and go test" had higher risk of falls. Symptoms of dizziness are commonly associated with postural instability and a broad-based, staggering gait pattern with unstable turn $^{23}$ which increase the risk of falls. Although dizziness is commonly related with vestibular dysfunction, symptoms of dizziness may also be a non-specific symptom and may reflect other problems such as cardiovascular disorders, orthostatic, drug side-effect hyperventilation, anxiety or depression ${ }^{24}$. The "get up and go test" assesses the balance and stability of the elderly. Comparison with other studies is limited as almost all studies reported timing of completing the test rather than difficulty in performing the test. However, having poor performance of gait and balance test is able to predict fall among the elderly ${ }^{11}$.

Polypharmacy has also been found to be one of the factors associated with falls among the elderly. Majority of the elderly in this study who took polypharmacy have poorer health status and and may have side effect from both blood pressure and glucose lowering medication which is a predictor of falls ${ }^{25}$. From the individual medication perspective, this study did not find any association between falls and the type of medications such as diabetic, antihypertensive, antidepressants and cardiogenic 
medications. The literature has suggested polypharmacy, the combination of four or more medications, has more risk for fall among elderly rather than individual medications ${ }^{25}$.

This study strength was a population based study which looked at a whole administrative area of Kota Bharu with samples taken from all twelve health clinics. Results from this study may represent whole community-dwelling elderly in Kota Bharu. A population-based study allows a clearer picture of the actual prevalence of fall and its associated factors in the population.

Some limitations of this study include, self-reporting of experience of falls and diseases, prescribed medication and health conditions which were exposed to a selection of response and recall bias. Furthermore, the data were collected from a screening service where the sick-well may be over represented. For some of these conditions, the numbers of condition was too small, perhaps pointing towards the sick-well attending screening services. In this study, only BMI were used as anthropometric measurement for obesity although there is other assessment which can be utilized for obesity assessment of the elderly such as knee height or arm span. However, these were not utilised in the screening method in this study. Such limitation is related to secondary data use.

Table 3: Multiple Logistic Regression of sociodemographic, body mass index, and other factors associated with falls among the screened elderly in Kota Bharu, Kelantan

\begin{tabular}{|c|c|c|c|c|c|c|c|c|}
\hline \multirow[t]{2}{*}{ Variable } & \multicolumn{8}{|c|}{ Adjusted Odds Ratio (95\% Confidence Interval) } \\
\hline & \multicolumn{2}{|c|}{ Model 1} & \multicolumn{2}{|r|}{ Model 2} & \multicolumn{2}{|c|}{ Model 3} & \multicolumn{2}{|c|}{ Model 4} \\
\hline Age $\geq 75$ years old & $\begin{array}{l}4.1 \\
1\end{array}$ & $\begin{array}{l}(2.38 \\
7.09)^{* * *}\end{array}$ & $\begin{array}{l}5.1 \\
5\end{array}$ & $\begin{array}{l}(2.83 \\
9.36)^{* * *}\end{array}$ & $\begin{array}{l}5.0 \\
4\end{array}$ & $\begin{array}{l}(2.72 \\
9.35)^{* * *}\end{array}$ & $\begin{array}{l}5.6 \\
3\end{array}$ & $\begin{array}{l}(2.90 \\
10.90)^{* * *}\end{array}$ \\
\hline Female & $\begin{array}{l}0.7 \\
5\end{array}$ & $\begin{array}{l}(0.46 \\
1.22)\end{array}$ & $\begin{array}{l}0.7 \\
1\end{array}$ & $\begin{array}{l}(0.42 \\
1.19)\end{array}$ & $\begin{array}{l}0.6 \\
5\end{array}$ & $(0.38,1.11)$ & $\begin{array}{l}0.4 \\
8\end{array}$ & $\begin{array}{l}(0.25 \\
0.91)^{*}\end{array}$ \\
\hline Employed & $\begin{array}{l}0.2 \\
2\end{array}$ & $\begin{array}{l}(0.07 \\
0.76)^{*}\end{array}$ & $\begin{array}{l}0.2 \\
1\end{array}$ & $\begin{array}{l}(0.06 \\
0.76)^{*}\end{array}$ & $\begin{array}{l}0.0 \\
7\end{array}$ & $\begin{array}{l}(0.01 \\
0.36)^{* *}\end{array}$ & $\begin{array}{l}0.0 \\
6\end{array}$ & $\begin{array}{l}(0.01 \\
0.41)^{* *}\end{array}$ \\
\hline Underweight & & & $\begin{array}{l}0.3 \\
9\end{array}$ & $\begin{array}{l}(0.10 \\
1.52)\end{array}$ & $\begin{array}{l}0.3 \\
3\end{array}$ & $(0.08,1,40)$ & $\begin{array}{l}0.3 \\
9\end{array}$ & $(0.09,1.75)$ \\
\hline Overweight & & & $\begin{array}{l}0.7 \\
1\end{array}$ & $\begin{array}{l}(0.36 \\
1.39)\end{array}$ & $\begin{array}{l}0.5 \\
8\end{array}$ & $(0.29,1.17)$ & $\begin{array}{l}0.4 \\
9\end{array}$ & $(0.23,1.04)$ \\
\hline Obese & & & $\begin{array}{l}4.2 \\
0\end{array}$ & $\begin{array}{l}(2.15 \\
8.20)^{* * *}\end{array}$ & $\begin{array}{l}3.3 \\
0\end{array}$ & $\begin{array}{l}(1.66 \\
6.59)^{* *}\end{array}$ & $\begin{array}{l}2.3 \\
0\end{array}$ & $\begin{array}{l}(1.06, \\
4.98)^{*}\end{array}$ \\
\hline Dizziness & & & & & $\begin{array}{l}11 . \\
82\end{array}$ & $\begin{array}{l}(2.57 \\
54.49)^{* *}\end{array}$ & $\begin{array}{l}11 . \\
35\end{array}$ & $\begin{array}{l}(2.19 \\
58.70)^{* *}\end{array}$ \\
\hline Imbalance & & & & & $\begin{array}{l}7.0 \\
2\end{array}$ & $\begin{array}{l}(2.42 \\
20.38)^{* * *}\end{array}$ & $\begin{array}{l}8.7 \\
5\end{array}$ & $\begin{array}{l}(2.71 \\
28.21)^{* * *}\end{array}$ \\
\hline $\begin{array}{l}\text { Polypharmacy } \\
\text { Diabetes medication }\end{array}$ & & & & & & & $\begin{array}{l}3.5 \\
6\end{array}$ & $\begin{array}{l}(1.26 \\
10.09)^{*}\end{array}$ \\
\hline $\begin{array}{l}\text { Anti-hypertensive } \\
\text { medication }\end{array}$ & & & & & & & $\begin{array}{l}2.2 \\
6 \\
0.5 \\
3\end{array}$ & $\begin{array}{l}(0.49, \\
10.50) \\
(0.17,1.66)\end{array}$ \\
\hline Diabetes Mellitus & & & & & & & $\begin{array}{l}0.7 \\
4\end{array}$ & $(0.18,3.08)$ \\
\hline Hypertension & & & & & & & $\begin{array}{l}1.3 \\
1\end{array}$ & $(0.44,3.91)$ \\
\hline Waist circumference & & & & & & & $\begin{array}{l}2.7 \\
0\end{array}$ & $\begin{array}{l}(1.38 \\
5.28)^{* *}\end{array}$ \\
\hline
\end{tabular}

P value $:^{*}<0.05^{* *}<0.01^{* * *}<0.00$

\section{CONCLUSION}

Falls occur in a quarter of the elderly population in Kota Bharu. Identification of associated factors for falls as assessed through health screening programme among the elderly is an important step in safe-guarding the health of the elderly in the community. Given the multiple factors which associated with falls, falls prevention programme such as weight management programme should be 
made more comprehensive to promote stability and better health, thus prevent the elderly from falling

\section{Conflict of interest}

The authors declare no potential conflict of interest.

\section{REFERENCES}

1. Department of Statistics Malaysia. Population Projection (Revised), Malaysia, 2020-2040.2016

2. Department of Statistics Malaysia. Current Population Estimates, Malaysia, 2020.

2. Azidah AK, Hasniza H, Zunaina E. Prevalence of Falls and Its Associated Factors among Elderly Diabetes in a Tertiary Center, Malaysia. Curr Gerontol Geriatr Res. 2012 Jan 1;2012.

4. Rizawati M, Mas Ayu S. Home environment and fall at home among the elderly in Masjid Tanah Province. Journal of Health and Translational Medicine. 2008 Dec 29;11(2):72-82.

5. Sazlina, S., Krishnan, R., Shamsul, A., Zaiton, A. \& Visvanathan, R. (2008). Prevalence of falls among older people attending a primary care clinic in Kuala Lumpur, Malaysia. Jurnal Kesihatan Masyarakat, 14(1), 11-16.

6. Himes CL, Reynolds SL. Effect of obesity on falls, injury, and disability. J Am Geriatr Soc. Jan 2012;60(1):124-129.

7. Fjeldstad C, Fjeldstad AS, Acree LS, Nickel KJ, Gardner AW. The influence of obesity on falls and quality of life. Dynamic Medicine. 2008;7(1):4.

8. Mitchell RJ, Lord SR, Harvey LA, Close JC. Obesity and falls in older people: Mediating effects of disease, sedentary behavior, mood, pain and medication use. Arch Gerontol Geriatr. 2015 Jan $1 ; 60(1): 52-8$.

9. Department Of Statistics Malaysia. Preliminary Count Report, Population And Housing Census Of Malaysia. 2010.

10. Family Health Development Division. Health Status Screening For Older Person (Saringan Status Kesihatan Warga Emas) BSSK/WE/2008 Pind. 1/2013, Ministry Of Health of Malaysia. 2013.

11. Azhar $A H$, Yusof SM. Fall Risk Factors among Malaysian Older Adults. Journal Of
Physical Activity, Sports \& Exercise. 2013;1(1).

12. Malaysia MoH. Malaysia Clinical Practice Guideline: Management of Obesity 2004.

13. Zamboni M, Mazzali G, Zoico E, et al. Health consequences of obesity in the elderly: a review of four unresolved questions. International journal of obesity. 2005;29(9):1011-1029.

14. Malaysia MOH. Malaysia Clinical Practice Guideline: Management of Hypertension 2013.

15. Mathias $S$, Nayak $U$, Isaacs $B$. Balance in elderly patients: the" get-up and go" test. Arch Phys Med Rehabil. 1986;67(6):387389.

16. Lin C-H, Liao K-C, Pu S-J, Chen Y-C, Liu M$\mathrm{S}$. Associated factors for falls among the community-dwelling older people assessed by annual geriatric health examinations. PLOS One. 2011;6(4):e18976.

17. Jeon BJ. The effects of obesity on fall efficacy in elderly people. J Phys Ther Sci. Nov 2013;25(11):1485-1489.

18. WHO EC. Appropriate body-mass index for Asian populations and its implications for policy and intervention strategies. Lancet (London, England). 2004;363(9403):157.

19. Blaum CS, Xue QL, Michelon E, Semba RD, Fried LP. The association between obesity and the frailty syndrome in older women: the Women's Health and Aging Studies. J Am Geriatr Soc. 2005;53(6):927-934.

20. Hubbard RE, Lang IA, Llewellyn DJ, Rockwood K. Frailty, body mass index, and abdominal obesity in older people. The Journals of Gerontology Series A: Biological Sciences and Medical Sciences. 2010;65(4):377-381.

21. Quandt SA, Stafford JM, Bell RA, Smith SL, Snively BM, Arcury TA. Predictors of falls in a multiethnic population of older rural adults with diabetes. J Gerontol A Biol Sci Med Sci. Apr 2006;61(4):394-398.

22. Honeycutt PH, Ramsey P. Factors contributing to falls in elderly men living in the community. Geriatr Nurs. Sep-Oct 2002;23(5):250-255.

23. Ambrose AF, Paul G, Hausdorff JM. Risk factors for falls among older adults: A review of the literature. Maturitas. 2013;75(1):51-61. 
24. Rubenstein LZ. Falls in older people: epidemiology, risk factors and strategies for prevention. Age and ageing. 2006;35(suppl 2):ii37-ii41.
25. Helgadottir B, Laflamme L, MonarrezEspino J, Moller J. Medication and fall injury in the elderly population; do individual demographics, health status and lifestyle matter? BMC Geriatr. 2014;14:92. 